\title{
A TERMINOLOGIA INDÍGENA NA FALA DO AMAZÔNIDA
}

\author{
LA TERMINOLOGÍA INDÍGENA EN LA HABLA DEL AMAZONIDA
}

\section{Maria Odaisa Espinheiro de Oliveira - odaisa@ufpa.br}

Doutora em Ciência da Informação pela Universidade Complutense de Madrid - Espanha. Professora na Graduação da Faculdade de Biblioteconomia e da Pós-graduação em Serviço Social na Universidade Federal do Pará (UFPA).

\section{Resumo}

A Representação Simbólica das Narrativas Populares da Amazônia Paraense como Linguagem de Informação (RESNAPAP), é um projeto de pesquisa da Faculdade de Biblioteconomia da Universidade Federal do Pará, no Brasil, que vem estudando a terminologia através de narrativas orais. O objetivo do trabalho é conhecer a terminologia indígena de termos retirados de narrativas orais. Para alcançar esse objetivo, foram recolhidas, pelo projeto "O Imaginário nas Formas Narrativas Orais da Amazônia Paraense (IFNOPAP)", 102 narrativas em dois municípios da Amazônia Paraense localizados as margens de dois importantes rios de concentração indígena: um no município de Cametá, próximo ao rio Tocantins, e o outro no município de Altamira, próximo ao rio Xingu. Esse artigo apresenta os termos, que o projeto RESNAPAP denomina de culturais, vistos como unidades lexicais da linguagem natural representativa da realidade sociocultural do amazônida. Assim, os termos de origem indígena foram organizados para se observar a contribuição lexical do étimo indígena no português falado da Amazônia e, também, para ser representado pelas tradições históricas e socioculturais.

\section{Palavras-Chave}

Terminologia indígena; Classificação; Altamira; Cametá; Amazônia Paraense. 


\section{INTRODUÇÃO}

O conhecimento coletivo é quase sempre lingüisticamente construído e se desenvolve no curso da evolução da sociedade para ser representado na dependência de tradições históricas e socioculturais. A linguagem, por sua vez, como um dos meios de estruturação da sociedade é responsável pela estruturação das relações comunicativas, da representação da realidade e, portanto, do conhecimento. Isto porque o conhecimento coletivo válido é quase sempre um conhecimento lingüístico constituído que se desenvolve no curso da evolução da sociedade.

Nesta observação, pode-se dizer que qualquer língua é culturalmente marcada pela representação da realidade da sociedade. Logo, este fenômeno como mostra Marques (1995), transparece em todos os níveis de estruturação lingüística, acionados pelas diversas práticas cotidianas. Contar histórias é uma dessas diversas práticas, que realizadas por populares tornam-se importantes para 0 estudo de terminologia desenvolvido pelo projeto RESNAPAP.

Assim, na pesquisa realizada, o objeto de estudo é o termo cultural, considerado no âmbito do RESNAPAP, como unidade lexical da linguagem natural, portador de informação da língua e da cultura, elucidado no discurso por meio da fala do amazônida.

Nos termos considerados culturais, também é observado nos aspectos lexicais, a presença dos termos de origem indígena, como espelho da vida de um povo. Como observa Lobo (1999, p.77) "o léxico é dentre os componentes de um sistema lingüístico, a face mais nítida da dinâmica cultural". É por isso que a língua espelha a vida de um povo, mostrando os fatos que o tempo $e$ as mudanças estruturais impõem ao homem. Logo, isto está relacionado com a cultura amazônica, devido um marcante contato entre o português e o índio. Daí que nas narrativas orais podem-se encontrar os sinais das diferentes épocas, no diálogo com os homens e, destes com a natureza.

A terminologia, ao arrolar termos de um domínio do conhecimento, designa conceitos. Mas, esses conceitos fazem parte de uma área especializada que são definidos de acordo com o contexto. É o caso das narrativas orais em que os termos aparecem dependendo do espaço onde é contada a história e, muitas vezes, não é conhecida a origem do léxico. Assim, se a sociedade se expressa por meio da língua, é de se esperar que essa língua a identifique, delimitando territórios, marcando espaços culturais, sendo fator 
decisivo na determinação da identidade étnica. A sociedade tende a eleger aspectos lingüísticos como marcas culturais, identificadores de pessoas pertencentes a uma região e um país. De fato a língua tem esse papel de constituir culturalmente o homem.

Quanto aos termos de etimologia indígena, a pesquisa mostra uma classificação a partir das categorias de assuntos, determinadas pelo RESNAPAP, nas áreas de Altamira e de Cametá onde foram recolhidas as histórias. Assim, os termos classificados nessas categorias, facilitam o estudo para a organização e a representação do conhecimento a fim de melhor recuperação da informação.

\section{TERMINOLOGIA NO DOMÍNIO DO CONHECIMENTO}

Nos artigos científicos podemos observar que os estudos de terminologia ampliam suas fronteiras, não só como disciplina de uma formação no campo da lingüística, mas também em diferentes estudos, abrangendo a tradução, a lingüística, a ciência da informação, a biblioteconomia e outros. Nesses estudos, a terminologia tem como unidade padrão o termo que é uma unidade lexical com um conteúdo específico, dentro de um domínio específico. Logo, o conjunto de termos de uma área específica chama-se terminologia. O termo como signo lingüístico das chamadas linguagens de especialidade ${ }^{1}$ passa a ser analisado em seus vários aspectos.

Para Barros (2004) são importantes a análise terminológica e a análise conceptual. Essas análises constituem dois passos fundamentais na pesquisa terminológica em relação ao termo e ao conceito. Isto porque os termos e os conceitos são identificados, delimitados e estudados em contextos, como um elemento muito importante no estudo de uma terminologia. Mas, como observam Krieger e Finatto (2004), o léxico temático, como um componente lingüístico, está a serviço de comunicações especializadas devido os termos transmitirem conteúdos próprios de cada área.

No entanto, em se tratando de terminologia cultural, como mostra Oliveira (2000), ela representa os termos que fazem parte do universo do informante e do seu posicionamento no contexto das histórias, designando os elementos da cultura da comunidade onde habita, condizente com a realidade da região onde foi recolhida a história.

Além disso, as características de variação, no universo da terminologia, no entendimento de Faulstich (1995), revelam peculiaridades próprias a serem estudadas. Essa autora mostra o objeto de estudo a ser realizado da disciplina

\footnotetext{
${ }^{1}$ Linguagem de especialidade está apoiada na tradição lingüística de que linguagem seria a língua em uso.
} 
denominada de Socioterminologia, que requer método próprio para sistematização de termos e de variantes.

\section{TERMINOLOGIA NA INTERFACE COM A CIÊNCIA DA INFORMAÇÃO}

Importante observar que a terminologia pode ser estudada para diferentes finalidades em diversas áreas. Assim, o estudo na interface da Ciência da Informação vem abordar o entendimento da interdisciplinaridade, como a transferência de métodos de uma disciplina para outra.

No que compete a elaboração de um sistema de classificação, com o objetivo de melhor recuperar a informação, alguns estudos norteiam o processo de execução do ato de classificar/agrupar os conceitos, o que sem esses estudos, torna-se difícil à organização do conhecimento humano. Pombo (1988) mostra que classificar é organizar, ordenar, reunir segundo características comuns.

Dessa maneira, para ser elaborado um sistema de classificação, primeiramente deve-se definir cada unidade que constitui tal sistema, na medida em que as classes reúnem as unidades a partir da relação entre os conceitos. No entanto, como observam Campos, Souza e Campos (2003, p.12) para a prática da relação entre os conceitos são necessários alguns "movimentos" como: a relação categorial; identificar como os objetos de mesma natureza se relacionam para depois fazer a análise de como o objeto se constitui para saber quais são suas partes e elementos.

Podemos ainda citar a visão da Teoria Geral da Terminologia, no que diz respeito aos conceitos e suas relações de dependência. Converge com a própria acepção de sistema quando é observado o conjunto de elementos relacionados entre si de modo coerente.

\section{A TERMINOLOGIA INDÍGENA EM NARRATIVAS ORAIS DE ALTAMIRA E CAMETÁ}

A terminologia indígena, estudada neste trabalho, partiu de narrativas recolhidas em dois municípios do estado do Pará: o de Altamira, situado às margens do rio Xingu e o de Cametá, situado às margens do rio Tocantins. Assim, os termos culturais, símbolos lingüísticos portadores de informação da língua e da cultura, estudados nas narrativas de Altamira e Cametá totalizam um corpus de 635 termos, registrados em ficha terminológica com seus respectivos contextos.

Vale ressaltar que para o conhecimento do termo em Altamira e em Cametá foram analisadas 89 narrativas orais populares, recolhidas pelo projeto IFNOPAP e uma narrativa fora do acervo, perfazendo um total de 90 narrativas que 
servem de material para os estudos do projeto RESNAPAP, cedidas por meio de parceria $^{2}$.

O município de Altamira é visto como - espaço da coleta das narrativas. O significado do termo é de origem geográfica e topônimo de origem portuguesa. O termo é formado por duas palavras "alta" e "mira". Nesse município está o rio Xingu, onde estão localizadas expressivas áreas destinadas à reserva indígena e ambiental, registrando presença significativa de povos indígenas de diversas etnias. Foram analisadas 64 narrativas orais do acervo do projeto IFNOPAP recolhidas neste município paraense.

Cametá é o nome de um dos municípios do estado do Pará. É um termo de origem tupi, que deriva de "Caa" (mato, floresta) e "muta" (uma espécie de degrau). Os primeiros habitantes dessa terra eram os integrantes da tribo Camutá.

Das narrativas recolhidas em Cametá foram analisadas 25 narrativas orais do acervo do projeto IFNOPAP e uma narrativa de $55 \mathrm{p}$. concedida para o projeto RESNAPAP por um habitante desse município chamado Manuel Valente, autor

${ }^{2} \mathrm{O}$ projeto IFNOPAP tem cedido as narrativas armazenadas em um banco de dados desde 1998. Mas o projeto RESNAPAP tem se utilizado também de outras narrativas. Desse modo, sobre o município de Cametá e Altamira foram utilizadas, neste trabalho, um total de 89 narrativas do projeto IFNOPAP e uma narrativa obtida em outra fonte de informação. da narrativa, perfazendo um total de 26 narrativas analisadas.

Quanto aos termos culturais estudados nas narrativas de Cametá e Altamira totalizam um corpus de 635 termos registrados, sendo 304 termos em narrativas de Cametá e 331 termos registrados em narrativas de Altamira.

Dos 304 termos analisados no total de 26 narrativas de Cametá, foram apresentados 43 étimos de origem indígena. Dos 331 termos analisados no total de 64 narrativas de Altamira, 39 termos apresentam étimo de origem indígena no total de 82 termos selecionados em narrativas de Altamira e Cametá com etimologia indígena.

No entanto, desse total de 82 termos indígenas, foram retirados 7 (sete) termos que representam forma de dizer como: Cuíra: adj. Etim. tupi. Inquieto, desassossegado, agitado, ansioso, aflito. (Cametá). Mutuca adj. Etim. (Tupi mu'tuka). Desconfiado, atento, de sobreaviso. (Cametá). Quiririm: adv. Etim. tupi. Pouco movimento, calmaria, devagar. (Cametá). Tuíra adj.Etim. (Tupi tuir (pardo, cinzentado'). Diz-se do açaí preto que apresenta manchas cinzentas em sua casca. (Cametá). Tipitingas: adj. Etim. Tupi (tipi'tiga'turvo'). Diz-se das águas que, apesar de barrentas, são esbranquiçadas. (Cametá). Achi interj. Etim. (tupi). Expressa desdém, 
espanto etc. (Cametá). Sapecar v. Brasil como moradia de uma ou mais Etim. (Tupi Sa'pek). Jogar (Altamira), famílias. Sinonímia: cabana. (Altamira).

totalizando 75 termos indígenas para o estudo da classificação divididos em 14 categorias.

Taba s.f. Etm. (Tupi 'tawa'). Aldeia indígena. (Altamira).

Taboca s.f. Etm. (Tupi ta 'woka' haste

\subsection{Classificação dos termos indígenas por categoria}

A classificação dos termos partiu do corpus terminológico indígena retirados das narrativas de Altamira e de Cametá. As categorias forma determinadas para facilitar a classificação de acordo com o significado no contexto narrativo. Cada categoria tem os termos relacionados, juntamente com o gênero, a origem do nome na língua indígena e sua definição, seguido da identificação do nome do município onde foi recolhida a história.

Assim as quatorzes (14) categorias, criadas para agrupar os termos, são listadas em ordem alfabética e os termos agrupados de acordo com o entendimento do conceito no contexto da história.

\section{a) Arquitetura}

Jirau s.m. Etim. (Tupi yulra). Espécie de pia de madeira bastante rústica colocada geralmente na janela pela parte externa da casa. (Cametá).

Oca: s. f. Etim. (Tupi óka'). Construção de madeira, entretecida e coberta por fibras vegetais, geralmente de planta circular, usado pelos indígenas do ou oca ou furada de planta). Pode ser usado como pequena casa de negócio. (Altamira). TOTAL $=4$ termos, sendo 3 retirados de Altamira e um de Cametá.

\section{b) Assombração}

Meuã s.f. Etm. (Tupi me'wã). Transformação de alguém ou alguma coisa em assombração para assustar, amedrontar. (Cametá). TOTAL= 1 termo retirado de Cametá.

\section{c) Culinária}

Beiju s.m. Etm. (Tupi mbeiú ou mbe'yú "o enrolado, o enroscado"). Alimento característico indígena e amplamente descrito pelos cronistas do século XVI. No geral, é circular, feito de tapioca ou mandioca, com ou sem leite de coco, ou castanha do Pará. (Cametá e Altamira).

Tucupi s.m. Etm. (Tupi-guarani 'ticu sumo, pi coisa crua'). Sumo que resulta da mandioca descascada e ralada. Esse líquido decantado e exposto ao sol com sal, pimenta e alho, constitui o <tucupi simples>, altamente venenoso. Mas quando levado ao fogo e fervido <tucupi cozido>, o qual é usado no preparo do 
tacacá, em molhos de pimenta e pratos diversificados. (Cametá).

Crueira s.f. Etim. (Tupi Kuru'era). Sobra de mandioca ralada que não passou na peneira, onde se apura a massa que se converte em farinha. É utilizada para fazer mingaus e bolinhos. (Cametá). TOTAL $=3$ sendo 2 termos de Cametá e um de Cametá e Altamira.

\section{d) Etnia}

Caboco (caboclo) s. m. Etm. (Tupi Kari"wora"). Da cor de cobre, acobreado. Mestiço de branco com índio. (Cametá e Altamira).

Bororó s.m. Etm. (Tupi).Tribo indígena pertencente ao grupo dos bororos. Grupo indígena que habita o leste de Mato Grosso e também tribo quase isolada da civilização, que vive na costa da Austrália $^{3}$. (Altamira).

Mundurucu s.m. Etm. (Tupi munduruku). Indígena pertencente ao grupo dos mundurucus. Família lingüística do tronco tupuí falada pelos mundurucu. Grupo indígena que habita o sudeste do Pará (áreas indígenas Cayabi, Mundurucus, mundurucu II, Praia do Índio, Praia do Mangue, Sai-Cinza), o leste do Amazonas (Terras indígenas Coatá-laranjal e São José do Cipó) e o este do Mato

\footnotetext{
${ }^{3}$ Retirado da história índios Bororós, contada por José
} Augusto Carvalho de Araújo.
Grosso (Reserva indígena Apiaká-kayabi). (Altamira).

Tucanos s.m. Etm.

(Tupi tu'kano).Grupos indígenas cujas línguas pertencem à família lingüística tucano; grupo indígena que habita no noroeste do Amazonas. Áreas indígenas no alto rio Negro, médio rio Negro I, médio rio Negro II, Pari Cachoeira I, II,III, Taracuá, Uneiuxi, Yaureté I e II e reserva Balaio e na Colômbia. (Altamira).

Tupinambá s.m. Etm. (Tupi tu'pi + na-mba descendentes do tupi). Designação comum a diversas tribos tupi-guarani que habitam o litoral do Brasil no século XVI. (Altamira).

Xipaia s. 2g. Indígenas dos xipaia, tribo extinta tupi que habitava as margens do rio Iriri, afluente do Xingu. Grupo indígena que habita o sudeste do Pará (Área indígena Curuá e Terra indígena xipaia-Curuaya). Xipaia Tambe é o nome da língua falada por esse grupo (língua da família lingüística juruna). (Altamira). TOTAL $=6$ termos, sendo 5 de Altamira e um de Altamira e Cametá.

\section{e) Fauna}

Anu: s.m. Etim. (Tupi a'nu). Designação comum às aves ccuculiformes, cosmopolitas, da família dos cuculídeos, gênero crotophaga e Guira, que possuem bico forte e cauda muito longa e graduada. Sinonímia: Ani, anum. (Altamira). 
Arara: s.f. Etim.(Tupi. a'rara'). Designação comum de algumas aves psitaciformes da família dos psitacídeos, (Anodorhynchus, Ara e América Latina), possuem grandes portes e são dotadas de bico alto, recurvado e de cauda longa. (Altamira).

Caititu s.m. Etim. (Tupi Taite'tu'). Porco do mato, mamífero artiodátilo da família dos taiaçuídeos (Tayassu tajacu), diurno e florestal, encontrado dos E.U.A, ao norte da Argentina, com cerca de $90 \mathrm{~cm}$ de comprimento e pelagem cinza-escura com uma faixa branca no pescoço, em forma de colar. Vive em bandos de até 20 indivíduos e sua carne é apreciada. Sinonímia: Porco-do-mato, cateto, catetu, catete, pecari, caititu, caitatu, taitatu. (Altamira)

Capivara s.f. Etm.(Tupi kapii'gwara). Hydrochocrus hydrochoeris L.; mamífero cavídeo distribuído pela região cisandina da América do Sul. (Altamira).

Cotia Etim. (Tupi aku'ti). Variante lingüística de cutia. Designação comum aos roedores do gênero Dasy procta, da família dosdasiproctídeos, representados no Brasil por cinco espécies com até $60 \mathrm{~cm}$ de comprimento e $4 \mathrm{~kg}$, pelagem curta e áspera, escura no dorso e esbranquiçada, ou amarelada nas partes inferiores, e cauda muito curta. Sua carne é apreciada na culinária. Sinonímia: Acouti, acuchi, acuti, aguti. (Altamira).
Guariba s.2g. Etm. (Tupi gwa'riwa guara'individuo'+aiba'feio, mau'). Nome de vários macacos da América do Sul e Central do gênero Alouata (macacos gritadores), providos de barba; bugio. (Cametá)

Jabuti s.m. Etm. (Tupi Yawo'ti). Designação comum aos quelônios terrestres e herbívoros da família dos testudinídeos, de carapaça alta, em forma de domo, patas posteriores tubulares, semelhantes às dos elefantes, dedos curtos com garras e movimentos lentos. (Altamira).

Jacaré: s. m. Etim. (Tupi yara're'). Nome comum a diversas espécies de crocodilianos, do gênero Caiman que vivem nos rios e lagos (Altamira).

Jacundá s.m. Etim. (Tupi yaku'nda). Designação comum a várias espécies de peixes teleósteos, ciclídeos, gênero Grenicichia Heckel, de aspecto semelhante ao da traíra e cuja nadadeira dorsal é dividida em uma parte espinhosa e outra ramosa, unidas, que ocupam quase todo o dorso, tendo muitas espécies um ocelo típico na cauda. (Cametá).

Jibóia s.f. Etim. (Tupi Yi'mboya). Grande serpente arborícola da família dos boídeos (Boas constrictor), encontrada do México ao norte da Argentina, com até $4 \mathrm{~m}$ de comprimento e dorso amarelo, castanho 
ou cinza, com manchas ovais avermerlhadas. (Altamira).

Mapará: s. m. Etim. (Tupi *mapa'ra'). Peixe teleósteo, siluriforme, da família dos hipoftalmídeos (Hypophthalmus edentatus), encontrado na Amazônia e no rio Paraná, de dorso azulado, ventre esbranquiçado, olhos situados sobre a articulação mandibular, e cuja carne é considerada de boa qualidade. Sinonímia: cangata, mandubi, mapará-de-Cametá, mapurá. (Cametá).

Mucura: s. m. Etim. (Tupi mu'kura'). Didelphys marsupialis. Mamífero marsupicial noturno da família Didelphidae, que ao sentir-se ameaçado, exala um odor fétido. Vive em árvores e se alimenta de frutos, ovos, insetos e pequenos animais. (Cametá)

Mutum: s. m. Etim. (Tupi mi'tu). Designação comum a várias aves galiformes da família dos Cracídeos, gênero Grax $L$ e Mitu, com várias espécies ameaçadas de extinção, de plumagem geralmente negra, topete com penas encrespadas ou lisas e bico com cores vivas. (Altamira).

Paca s.f. Etim. (Tupi 'paka'). (Cuniculus paca L.). Mamífero roedor, cuniculídeo, distribuído por quase toda região cisandina, de dorso escuro e lustroso, lados do corpo com três a cinco listras longitudinais irregulares, brancas, ventre branco e cauda reduzida a um tubérculo nu. (Altamira).

Perereca: s.f. Etim. (Tupi pere'rreka). Designação comum aos anfíbios anuros, arborícolas, de ventosas nos dedos, sobretudo, os da família dos hilídeos. O número de espécies de pererecas no Brasil sobe a mais de 80 . Sinonímia: raineta. (Altamira).

Piaba s.f. Etim. (Tupi 'piawa'). Designação comum a várias espécies de peixes fluviais. Teleósteos, caraciformes, caracídeos, especialmente dos gêneros Leporinus Spix e Schizodon Agass, de boca pequena, dentição forte e que se alimentam de matéria vegetal e de animais em decomposição. (Altamira).

Poraquê s.m. Etim.Tupi (Pura'ke). Peixe teleósteo gimnotiforme e da família dos eletroforídeos (Electrophorus electricus).(Cametá).

Quatí s. m. Etim. (Tupi Kwa'tí) Designação comum a diversos esquilos do gênero Sciurus, encontrados especialmente na Amazônia. (Altamira).

Saúva: s.f. Etim. (Tupi isa'uwa'). Designação comum às formigas, espécie do gênero Atta, da família dos formicídeos, com cerca de 200 espécieis, privativas do novo mundo e abundantes na região neotropical, cortam pedaços de folhas e carregam para os ninhos, a fim de criar os fungos que constituem seu alimento 
exclusivo; é uma das mais importantes pragas agrícolas do Brasil. Atta cephalotes da Amazônia e litoral do nordeste brasileiro que apresenta cabeça brilhante, lisa na parte superior e bastante pelosa na parte anterior. Sinonímia: Saúva-da-mata. (Altamira).

Tatu s.m. Etim.(Tupi tatu). Designação comum aos mamíferos Xenartros desdentados da família dos dasipodídeos, encontrados do sul dos E.U. à Argentina, com seis gêneros no Brasil e aproximadamente 11 espécies. (Altamira).

Tucunaré: s.m. Etim. (Tupi (tukuna're'). Peixe teleósteo, perciforme, da fam. Dos cicídeos (Cichla ocellaris), do rio Amazonas e afluentes, com até $60 \mathrm{~cm}$ de comprimento e $4 \mathrm{~kg}$ de peso, corpo prateado com três faixas transversais acima da linha lateral e um ocela na base da nadadeira em açudes no Nordeste e nas represas do Sul do Brasil; sua carne é muita apreciada, e a pele é utilizada para fabricação de couro. (Altamira).

Uirapurru s.m. Etim. (Tupi gwirapu'ru). Designação comum a várias espécies de aves passereformes, piprídea, especialmente, as mais coloridas dos gêneros Pipra L. , Chiroxipha Cab., Teleonema Reich. Seu canto, que só se ouve uns quinze dias por ano, ao amanhecer, é tido como melodioso, e diverso de qualquer outra ave, a ponto de, segundo a lenda, os outros pássaros todos se calarem para escutá-lo. (Altamira). TOTAL $=22$, sendo 16 termos de Altamira e 6 de Cametá.

\section{f) Flora}

Açaí s. m. Etim.(Tupi iwasa'i 'fruto que chora'). Euterpe oleracea. Fruta da palmeira de tronco fino e comprido de até $25 \mathrm{~m}$ de comprimento. (Cametá e Altamira).

Açaizeiro: s. m. Etim. tupi. Palmeira de tronco fino e comprido de até $25 \mathrm{~m}$ de comprimento; folhas grandes finalmente recortadas em tiras, de coloração verdeescura, atingindo freqüentemente $2 \mathrm{~m}$ de comprimento. O açaí se desenvolve tanto em terra firme como em áreas de várzea sujeitas às inundações periódicas. Do fruto se extrai vinho e o palmito, além de ser consumido, em forma de pasta funciona como anti-hemorrágico. (Cametá).

Aturiá: s. m. Etim. (Tupi 'aturi'a). Árvore leguminosa (Machaerium lunatum (L)), de ramos compridos e tortuosos, no baixo Amazonas e litoral do Pará e o Drepanocarpus ferox M., de campo de várzea da Amazônia. Esta planta ribeirinha arbustiva só vinga no estuário. Vive em família, debruçada na borda dos canais e ilhas. Tem o sinal da maré alta deixado pelo sedimento fluvial na ramaria. (Cametá).

Bacaba s.f Etm. (Tupi iwa'kawa < iwa 'fruta' + kawa 'gorda'). Oenocarpus 
bacaba; da família das Palmáceas, fruto da palmeira. Bebida, vinho, extraído do fruto do mesmo nome, de coloração creme, leitosa, conhecida popularmente como abacaba. Sinonímia: mucumucu, iuquicé. (Altamira).

Bacabeira s.f. Etm.(Tupi. Derivada de bacaba) Oenocarpus distichus Mart.; da família das Palmáceas; espécie de palmeira de $20 \mathrm{~m}$ de estirpe reto. Nativa da Amazônia. (Altamira).

Cabi: s. m. Etim. (Tupi kaa'pi). Variante lingüística de CAAPI, cabi ou gabi (Banisteria caapi). Cipó da família das malpighiáceas, nativa do Brasil (AM), cultivado por várias tribos indígenas, das quais se extrai um alcalóide alucinógeno, a banisternia ou harmina, presente no caule, usada na confecção do ayahuasca ou santo-daime, e que se encontra na casca e nas folhas usadas como fumo. Há certa confusão entre as variedades, pois consta que a espécie verdadeira é alucinógena. Também usada como amuleto por rezadeiras. (Cametá)

Cajá: s. f. Etim. (Tupi aka'ya). Fruto da cajazeira, árvore da família das Anacardiáceas (Spondia lútea $L$ ). O cajá é uma frutinha de casca lisa e fina, de cor alaranjada ou vermelha, muito aromático e de polpa suculenta, de sabor agridoce, que se presta ao preparo de refrescos, batidas, licores e sorvetes. É rica em sais minerais, como cálcio, fósforo e ferro, sendo freqüente nas várzeas e matas de terra firme e argilosa, podendo ser encontrado o ano todo. (Altamira).

Cipó: s. m. Etim. (Tupi isi>po). Designação comum às plantas lenhosas e trepadeiras, características das matas tropicais, de ramos delgados e flexíveis, que se fixam por meio de acúleos, de gavinhas ou por enrolarem-se aos caules e ramos de árvores e arbustos. (Cametá).

Envieira: s. f. Etim. (Tupi i'mbira). Designação comum a várias árvores que ocorrem no Brasil, da família das timeleáceas, especialmente do gênero Daphnopsis e Funifera. Suas folhas são venenosas para o gado. Das cascas se extraem as fibras para confecção de cordas e estopa. Sinonímia: embira, envireira, embireira, envira, embira-branca. (Cametá)

Macaxeira s.f. Etim. (Tupi maka'xera). Planta euforbiácea menor que a mandioca e sem os seus princípios tóxicos e de hastes não angulosas. (Manihot palmata Muell. Arg Manihot aypi pohl. Na Amazônia, há duas variedades: a branca e a de casca roxa ou do gentio. É utilizada na alimentação quando cozida, assada ou frita. (Altamira).

Mandioca: s. f. Etim. (Tupi mandi'oka'). Arbusto berbáceo da família das euforbiáceas (Manihot utilíssima), nativa da América do Sul, de folhas 
membranáceas, inflorescências ramificadas e frutos capsulares, muito cultivado por suas raízes tuberosas, de casca pardacenta e massa branca, contendo um suco leitoso, acre, e mais ou menos venenoso. A massa, rica em amido, é usada para a produção de farinha de mandioca, farinha d'água e ração animal. Sinonímia: aipi, aipim, aimpim, candinga, castelinha, macamba, maxera, pão-depobre, xagala. (Cametá).

Miritizeiro: s. m. Etim. (Tupi.). Mauritia flexuana $L$; palmeira muito alta própria de lugares alagados. Suas folhas servem para construção de telhados, é usado, também, na confecção de brinquedos e/ou artefatos (Cametá)

Mururé s.m. Etim. (Tupi mururi). Nome de duas árvores moráceas (Brosimopsis acutifólia e B. obovata). (Cametá).

Mututi: s. m. Etim. (Tupi *mutu'ti'). Nome comum a duas espécies de árvores da família das leguminosas: Etaballia guianensis e Pterocarpus draco. A primeira espécie, produz uma madeira de lei muito utilizada na construção naval. A segunda, produz uma madeira de qualidade inferior empregada como estaca na construção civil. A escarificação da sua casca faz gotejar uma resina líquida, vermelha $\mathrm{e}$ adstringente que logo coagula. (Cametá).
Piquiazeiro: s. m. Etim. Tupi. Caryocar villosum (Aubl.) Pers. Grande árvore de terra firme, da família das cariocaráceas, de boa madeira de tronco por vezes de enorme dimensão. Folhas trifoliadas, flores amarelas. Fruto oleaginoso. O óleo obtido da polpa é esbranquiçado e gordo sui-generis. A polpa quando cozida é comestível. Fornece mais de $60 \%$ de substância similar à manteiga, e é empregada na culinária. (Cametá).

$$
\text { Samaumeira s.f.Etm. }
$$

(Tupi sama'uma). Ceiba pentandra. Da família das bombáceas, nativa da América do Sul e da África. (Altamira). Tucumazeiro s.m. Etim. (Tupi tuku'ma). Astrocaryum tucumã. Palmeira que vai a $15 \mathrm{~m}$ de altura e possui espinhos longos e finos. (Cametá).

Tabaco: s. m. Etim. Tupi. Erva Anual de até $2 \mathrm{~m}$ (Nicotiana tabacum), da família das solanáceas, com folhas viscosas, no geral, ovado-lanceoladas, de até $60 \mathrm{~cm}$, flores róseas ou vermelhas, com tubo branco, em racemos dispostos em ampla panícula terminal e cápsulas elípticas ou ovóides. Nativa das Américas, é a mais cultivada para a produção de cigarros, charutos, rapé etc. e também como pesticida e vermicida. Sinonímia: erva-dogrão-prior, fumo, rapé. (Cametá). TOTAL= 17 sendo 12 termos de Cametá , 4 de Altamira e um de Altamira e Cametá. 


\section{g) Crença}

Muiractam: s. m. Etim. Tupi (mbiraki'tã). Artefato fabricado de argila que é retirada de um lago considerado sagrado pelas amazonas. Objeto talhado em pedra jade, ao qual se atribui qualidade sobrenatural de amuleto (Altamira). TOTAL $=1$ termo de Altamira.

\section{h) Tipo de Trabalho Coletivo}

Mutirão: s. m. Etim. Tupi. Mobilização coletiva para auxílio mútuo, especialmente, entre trabalhadores do campo, por ocasião de roçada, colheita etc. (Altamira). TOTAL= 1 termo de Altamira.

\section{i) Técnica de Trabalho}

Coivara: s. f. Etim. Tupi. (coibara). Quantidade de ramagens a que se põe fogo nas roçadas para desembaraçar o terreno e adubá-lo com as cinzas, facilitando a cultura. (Cametá)

Muquém: s. m. Etim. Tupi (moka'em). Variante lingüística de moquém. Grelha típica de assar o peixe ou a caça, a fogo lento. (Cametá). TOTAL $=2$ termos de Cametá.

\section{j) Instrumento de Trabalho}

Cacurí s.m. Etim.(Tupi Kakuri). Armadilha para pegar peixes. (Cametá).

Curral s. m.Etim. (Tupi). Lugar onde se junta e recolhe animais, como gado e peixes. (Altamira).
Matapi s.m. Etim.(Tupi mata'pi). Utensílio de pesca de forma alongada com as extremidades afuniladas, confeccionado com tala de miriti e de jacitara, utilizado na pesca do camarão. (Cametá).

Peconha s.m.Etim. (Tupi peko'in). Laço de corda que os trepadores de árvore apóiam os pés de encontro ao caule, para depois estes subirem com a força de suas pernas e braços. (Cametá). TOTAL $=4$ termos, sendo 3 de Cametá e um de Altamira.

\section{k) Mito}

Anhangá s.m. Etim.(Tupi a'ñanga). Anhangá quer dizer sombra, espírito. $\mathrm{O}$ anhangá traz para aquele que vê, ouve ou pressente frebre, loucura ou certo prenúncio de desgraça. (Cametá).

Caipora: s.m. Etim. (Tupi kaa'pora). O caipora é o protetor dos animais e plantas da floresta. Sua atividade consiste em espantar os animais para que os caçadores não possam matá-los. Quando encontra um caçador no mato, o caipora começa a andar sem rumo certo até que o caçador se perca na floresta, não encontrando mais o caminho de volta para casa. Seu nome significa "habitante do mato". Sinonímia: urucubaca. (Altamira).

Curupira s. m. Etim.Tupi-guarani (kuru'pira'). O curupira é representado como um pequeno tapuio, com os pés voltados para trás e sem orifícios 
necessários para as secreções. Sua função é proteger florestas. (Cametá).

Saci: s. m. Etim. Tupi (*sa'si'). Entidade fantástica, negrinho de uma perna só, que fuma cachimbo e usa um barretinho vermelho, fonte seus poderes de magia e que, segundo a crença popular, diverte-se espantando o gado e espavorindo os viajantes nos caminhos solitários, com seus longos assobios no meio da noite. Sinonímia: Saci-Cererê, Saci-Pererê. (Altamira e Cametá).

Tintaperera: s.m. Etim. (Tupi matintape're).Variante lingüistica de MATINTAPERERA. Pessoa na terceira idade, que se transforma num pássaro de assobio forte e assustador. Para descobrir a identidade da matintaperera, costuma-se dizer a seguinte frase ao ouvir o assobio dela: "Matintaperera, passa de manhã em casa para pegar fumo". A primeira pessoa, que no dia seguinte aparecer para pegar o fumo, é considerada matintaperera. (Cametá). TOTAL $=5$ termos, sendo 4 termos de Cametá e um de Altamira.

\section{I) Utensilios Domesticos}

Apá: s. m. Etim. tupi. Colher em forma de pá que serve para mexer doces e outras iguarias. (Cametá). TOTAL= 1 termo de Cametá.

\section{m) Natureza e Habitar}

Capoeiral s.m. Etim.(Tupi Ko'pwera, Ko'roça' +powera'que já foi'). Grande área de mata onde medram grandes árvores. (Cametá).

Igarapé s.m. Etim. (Tupi iara'pé).Canal natural estreito e navegável por pequenas embarcações, que se forma entre duas ilhas fluviais ou entre uma ilha fluvial e a terra firme. (Cametá e Altamira). TOTAL=2 termos, sendo um de Cametá e um de Cametá.

\section{n) Papel Social}

$$
\text { Pajé s.m. Etim. (Tupi pa'ye). }
$$

Indivíduo responsável pela condução do ritualismo mágico e aquém se atribui autoridade xamanística de invocar e controlar espíritos, o que confere à sua ação encantatória, poderes oraculares, vaticinantes e curativos. (Cametá e Altamira). TOTAL $=1$ termo de Cametá e Altamira.

\section{CONSIDERAÇÕES FINAIS}

Da análise dos termos por categoria, as que apresentaram maior percentual foram: a categoria FAUNA com 26 termos, e a categoria FLORA com 17 termos. Na análise, da classificação dos termos por categoria, foi observado que 5 termos se repetem em narrativas de Altamira e Cametá, que são: açaí, beiju, caboco (caboclo), igarapé e pajé.

De acordo com as narrativas recolhidas, em Altamira e Cametá, muitas palavras de origem tupi ainda são citadas 
na fala dos amazônidas. A história mostra que o Brasil, na época de seu descobrimento, contava com índios que se expressavam através de línguas diferentes. Mas, apesar das perdas em seu número populacional, a cultura do índio através de sua linguagem permanece na Região Amazônica.

Nesta maneira de observar a linguagem e a cultura em uma parte da Região Amazônica, torna-se importante pesquisar para conhecer através das narrativas orais, não somente marcas de sua cultura como também, a importância da classificação das categorias para melhor recuperação em sistemas de informação.

Quanto a classificação foram criadas categorias para incluir os termos portadores de informação para melhor comunicação, no entendimento das narrativas orais contadas por populares em dois municípios da Amazônia paraense. Essa classificação é importante para a elaboração da linguagem a qual vai ser utilizada pelo sistema para melhor recuperação da informação.

\section{REFERENCIAS}

BARROS, Lídia Almeida. Curso básico de terminologia. São Paulo: EDUSP, 2004.
CAMPOS, Maria Luiza de Almeida; SOUZA, Rosali Fernandes de; CAMPOS, Maria Luiza Machado. Organização de unidades de conhecimento em hiperdocumentos: o modelo conceitual como espaço comunicacional para a realização da autoria. Ciência da Informação, Brasília DF, v. 32, n.2, p.7-16, maio/ago. 2003.

FAULSTICH, Enilde. Socioterminologia: mais que um método de pesquisa, uma disciplina. Ciência da Informação, Brasília DF, v.24, n.3, p.281-288, set./dez. 1995.

KRIEGER, Maria da Graça; FINATTO, Maria José Bocorny. Introdução à terminologia: teoria \& prática. São Paulo: Contexto, 2004.

LOBO, Telma de Carvalho. Léxico: espelho da história de um povo. In: SIMÕES, Maria do Socorro (Org.). Narrativa oral e imaginário amazônico. Belém: UFPA, 1999. p. 77-82.

MARQUES, Maria Emília Ricardo.

Sociolingüística. Lisboa: Universidade Aberta, 1995.

OLIVEIRA, Maria Odaisa Espinheiro de. A terminologia cultural no discurso oral popular Amazônico. In: SIMÕES, Maria do Socorro (Org.). Memória e comunidade: entre o rio e a floresta. Belém: UFPA, 2000. p. 93-102.

POMBO, Olga. Da classificação dos seres à classificação dos saberes. Revista da Biblioteca Nacional de Lisboa, Lisboa, n. 2, p. 19-33, primavera, 1988.

\section{Title}

The indigenous terminology in the Amazon's speech 


\section{Abstract}

The Symbolic Representation of the Popular Narratives of Paraense Amazonian as Language of Information (RESNAPAP) is a research project developed by the School of Librarianship at the Federal University of Para, Brazil, which has been studying the terminology through orals narratives. The objective of this work is to know the indigenous terminology of some terms extracted from indigenous oral narratives. To achieve this goal, it was collected, for the project The Imaginary in the Oral Narrative Forms of Paraense Amazonian (IFNOPAP), 102 narratives in two districts of the Paraense part of Amazonia which are located very close to the two most important rivers of indigenous concentration: the Cameta district, near the Tocantins River, and Altamira district near the Xingu River. The article presents the terms that the project RESNAPAP denominates as cultural, that are seen as lexical units of the natural language, which represents the socialcultural reality of the Amazonian. In this sense, the terms of indigenous origin were organized to observe the lexical contribution of the indigenous etymon in the Amazon's spoken Portuguese as well as to represent it by the historical and sociocultural traditions.

\section{Key Words}

Indigenous terminology; Classification; Altamira; Cameta; Paraense Amazonia

\section{Titulo}

La terminología indígena en la habla del amazonida

\section{Resumen}

La Representación Simbólica de las Narrativas Populares de la Amazonia Paraense como Lenguaje de Información (RESNAPAP), es un proyecto de investigación de la Facultad de Bibliotecología de la Universidad Federal do Pará, en Brasil, que viene estudiando la terminología a través de narrativas orales. El objetivo del trabajo es conocer la terminología indígena de términos retirados de narrativas orales. Para llegar en ese objetivo, fueron recogidas, por el proyecto "El Imaginario en las Formas Narrativas Orales de la Amazonia
Paraense (IFNOPAP)", 102 narrativas en dos municipios de la Amazonia Paraense, localizados en las márgenes de dos importantes ríos de concentración indígena: uno en el municipio de Cametá, en las proximidades del río Tocantins y el otro, en el municipio de Altamira, próximo al río Xingu. En este artículo son presentados los términos que el proyecto RESNAPAP denomina de culturales, vistos como unidades lexicales del lenguaje natural, representativa de la realidad sociocultural del amazonida. Así, los términos de origen indígena fueron organizados para observar la contribución lexical del étimo indígena en lo portugués hablado de la Amazonía y, también, para ser representado por las tradiciones históricas y socioculturales.

\section{Palabras-Clave}

Terminología indígena; Clasificación; Altamira; Cametá; Amazonia Paraense.

Recebido em: 17/06/2007

Aceito em: 09/06/2008 